\title{
Influence of Ion Beam and Carbon Black Filler Type on the Mechanical and Physico-Chemical Properties of Butadiene Acrylonitrile Rubber (NBR)
}

\author{
H. H. Hassan, \\ Physics Department, \\ Faculty of Science, \\ Cairo University, \\ Giza, Egypt
}

\author{
A. I. Aboud \\ Physics Department, \\ Faculty of Science, \\ Cairo University, \\ Giza, Egypt
}

\author{
M.A. El-Waily \\ Physics Department, \\ Faculty of Science, \\ Cairo University, \\ Giza, Egypt
}

\begin{abstract}
Five types of carbon black nanofillers, namely Intermediate Super-Abrasion Furnace ISAF (N220), High-Abrasion Furnace HAF-LS (N326), Fast Extruding Furnace FEF (N550), General Purpose Furnace GPF (N660) and Semi-Reinforcing Furnace SRF-HS (N774) were incorporated with butadiene acrylonitrile rubber (NBR) in order to improve its physical properties. Young's modulus was found to increase with nanofiller content. Percolation concentration was detected in mechanical as well as in Physico-chemical behavior. The experimental values of the normalized Young's modulus fit well with Pukanszky et al. model; taking into consideration the difference in carbon black-filler type. It is noticed that the characteristic time of swelling in toluene, $\tau$ is higher for NBR loaded with $30 \mathrm{phr}$ ISAF and for the rest of samples it increases with increasing of particle size. Finally oxygen ion beam irradiation for percolative loading NBR nanocomposites increases Young's modulus nearly by $2-3$ times.
\end{abstract}

Keywords: Carbon-black nanofiller; NBR; Nanocomposites; Young's modulus; Percolation threshold; maximum degree of swelling.

\section{INTRODUCTION}

Most commercial polymers may be classified as insulating, having volume resistivities of $10^{9} \mathrm{Ohm} \mathrm{cm}$ or more. However, their properties are extensively modified, to antistatic $\left(10^{4}-10^{9}\right.$ $\mathrm{Ohm} \mathrm{cm}$ ) or conductive (lower than $10^{4} \mathrm{Ohm} \mathrm{cm}$ ), by compounding, with fillers having the largest effect on properties[1,2]. In many cases, it is beneficial to introduce some level of electrical conductivity into a polymeric material $[3,4]$. The highly insulating polymers are susceptible to static build up. This may be a nuisance, attracting dust to the surface, or it may lead to damage of sensitive electronic parts, when manufacturing integrated circuits, for example. Even very low levels of surface conductivity will resolve this problem [5]. Organic based antistatic additives are available or alternatively conductive fillers such as carbon black, graphite, or metals may be added [5]. Antistatic agents are usually highly polar liquids, which form a surface film that is antistatic in character. This prevents the build-up of electrostatic charges on the surface of the product. This type of additive is normally added to lightcolored compounds, as most carbon-black-filled composites are inherently antistatic [1]; but the need of a white antistatic materials in industrial applications, such as textile manufacturing, leads one to use white metals as a filler. One of the most sensitive methods for determining the degree of dispersion of filler within a rubber compound is the measurement of its ac and dc electrical properties as well as mechanical properties under different conditions. Composites made with carbon black, long used for elastomer reinforcement, have recently replaced metals in several industrial applications. But, the need of white antistatic materials is still the demand of many technological applications. Their usefulness depends on how well their properties can be manipulated, which in turn requires an understanding of the controlling physical mechanisms involved [6].

Rubber nanocomposites have attracted many researchers due to their unique properties. In rubbers, fillers are used to achieve products with improved properties for end use applications. It is well known that for most of the applications, rubber must be reinforced with certain fillers such as carbon blacks (CB), silica, clay and so on. Rubber nanocomposites are prepared through different techniques such as melt mixing, mill mixing, solution mixing, latex stage mixing followed by a cocoagulation method and polymerization around the filler particles. As compared with microfiller-reinforced rubber, nanofiller-reinforced rubber exhibits high hardness, modulus, anti-aging and gas barrier properties. Therefore, the 
nanoconcept is highly relevant for rubber compounds since their applications require filler reinforcement.

Composites are used in a wide variety of products, from advanced spacecraft to sporting goods to joint implants. Metal doped polymer provides suitable properties for EMI shielding [7]. They are currently being used in various medical procedures and been developed as candidates for different types of sensing applications. The conductive and absorptive properties of insulating polymers doped with conducting fillers and the absorptive properties of unfilled-insulating polymers are sensitive to the exposure of gas vapors. Therefore, they can be used to monitor the existence and concentration of gases in environment [8].

Energetic ion beams play a vital role in the field of materials science [9]. Ion beam effect on the materials depends on the ion species, energy and influence [10]. The interaction of the ion with material is the deciding factor in the ion beam- induced material modification. Polymer ion implantation may induce irreversible changes in their macroscopic characteristics such as electrical and structural properties and surface related mechanical property. These changes are responsible to fundamental events like electronic excitation, ionization, chain scission and cross links as well as mass loss, which take place due to ion beam implantation. Therefore, the understanding of a certain structural rearrangements influences the properties of the polymeric materials and/or composites opens a way to design devices with required parameters.

The purpose of this study is to prepare five groups of carbon black/NBR nanocomposites loaded up to $100 \mathrm{phr}$, choose the most sensitive nanocomposite sample among each group; then investigate the effect of oxygen ion beam influence on its mechanical parameters as well as solvent penetration characteristics.

\section{EXPERIMENTAL MATERIALS}

Table 1 Composition of NBR samples with different concentrations of various carbon black filler types

\begin{tabular}{|l|l|l|l|l|l|l|l|l|l|l|l|}
\hline $\begin{array}{l}\text { Sample } \\
\begin{array}{l}\text { Ing } \\
(\mathrm{phr})^{\mathrm{a}}\end{array}\end{array}$ & $\begin{array}{l}\text { NX } \\
0\end{array}$ & $\begin{array}{l}\text { NX } \\
10\end{array}$ & $\begin{array}{l}\text { NX } \\
20\end{array}$ & $\begin{array}{l}\text { NX } \\
30\end{array}$ & $\begin{array}{l}\text { NX } \\
40\end{array}$ & $\begin{array}{l}\text { NX } \\
50\end{array}$ & $\begin{array}{l}\text { NX } \\
60\end{array}$ & $\begin{array}{l}\text { NX } \\
70\end{array}$ & $\begin{array}{l}\text { NX } \\
80\end{array}$ & $\begin{array}{l}\text { NX } \\
90\end{array}$ & $\begin{array}{l}\text { NX } \\
10 \\
0\end{array}$ \\
\hline NBR & $\begin{array}{l}10 \\
0\end{array}$ & $\begin{array}{l}10 \\
0\end{array}$ & $\begin{array}{l}10 \\
0\end{array}$ & $\begin{array}{l}10 \\
0\end{array}$ & $\begin{array}{l}10 \\
0\end{array}$ & $\begin{array}{l}10 \\
0\end{array}$ & $\begin{array}{l}10 \\
0\end{array}$ & $\begin{array}{l}10 \\
0\end{array}$ & $\begin{array}{l}10 \\
0\end{array}$ & $\begin{array}{l}10 \\
0\end{array}$ & $\begin{array}{l}10 \\
0\end{array}$ \\
\hline St. acid & 2 & 2 & 2 & 2 & 2 & 2 & 2 & 2 & 2 & 2 & 2 \\
\hline Zn O & 5 & 5 & 5 & 5 & 5 & 5 & 5 & 5 & 5 & 5 & 5 \\
\hline DOP. & 0 & 10 & 10 & 10 & 10 & 10 & 10 & 10 & 10 & 10 & 10 \\
\hline X & 0 & 10 & 20 & 30 & 40 & 50 & 60 & 70 & 80 & 90 & 10 \\
\hline TMTD & 2 & 2 & 2 & 2 & 2 & 2 & 2 & 2 & 2 & 2 & 2 \\
\hline IPPD & 1 & 1 & 1 & 1 & 1 & 1 & 1 & 1 & 1 & 1 & 1 \\
\hline 020 & & & & & & & & & & & \\
\hline S & 2 & 2 & 2 & 2 & 2 & 2 & 2 & 2 & 2 & 2 & 2 \\
\hline
\end{tabular}

${ }^{a}$ Part per hundred parts of rubber by weight.

Since sample properties depend on the method of preparation it is important that samples should be made under the same conditions [11,12]. In this work NBR (density $0.98 \mathrm{~g} / \mathrm{cm}^{3}$ and acrylonitrile content $34 \%$ supplied by TRENCO, Alexandria, Egypt) was used as polymer matrix, with five types of black fillers, namely Intermediate Super-Abrasion Furnace ISAF (N220), High-Abrasion Furnace HAF-LS (N326), Fast Extruding Furnace FEF (N550), General Purpose Furnace GPF (N660) and Semi-Reinforcing Furnace SRF-HS (N774) supplied by TRENCO, Alexandria, Egypt. Other compounding ingredients (supplied by Morgan Chemicals, Cairo, Egypt) such as zinc oxide and stearic acid (binary activators), tetramethylthiuram disulfide TMTD (semi-ultra-accelerator), Processing oil; dioctyl phthalate (DOP), (plasticizer), N-(1,3dimethylbutyle)-N-phenylenediamine

(IPPD(4020)) (antioxidant, antiozonant, antiflex and ageing retardant) and sulfur (vulcanizing agent) were used. These materials are compounded according to the recipe as listed in Table (1). For each filler type, NBR was loaded with different concentrations $(0,10,20,30 \ldots 100 \mathrm{phr})$ to achieve suitable physical properties for specific applications. The physical parameters of used fillers are shown in Table (2).

\section{Sample Preparation}

Ingredients of the rubber blend were mixed, according to the ASTMD 3182-89, on a two-roll laboratory mill of $170 \mathrm{~mm}$ diameter, 300-mm length, the speed of slow roll being $18 \mathrm{rpm}$ and gear ratio 1.4. The ingredients were added in the order as shown in Table (1). The compounded rubber was left for 24

Table 2 Physical properties of carbon blacks 


\begin{tabular}{|c|c|c|c|c|c|c|}
\hline $\begin{array}{l}\text { Black } \\
\text { grade }\end{array}$ & $\begin{array}{c}\text { ASTM } \\
\text { numbe } \\
r\end{array}$ & $\begin{array}{c}\text { Mean } \\
\text { particle } \\
\text { diamete } \\
\mathbf{r}(\mathbf{n m})\end{array}$ & $\begin{array}{c}\text { EmSA } \\
\quad \mathrm{a} \\
\left(\mathrm{m}^{2} / \mathrm{g}\right)\end{array}$ & $\begin{array}{c}\operatorname{BETN}_{2} \text { SA } \\
{ }^{b}\left(\mathrm{~m}^{2} / \mathbf{g}\right)\end{array}$ & $\begin{array}{c}\text { CTAB } \\
\mathrm{c} \\
\left(\mathrm{m}^{2} / \mathrm{g}\right)\end{array}$ & $\begin{array}{c}\text { DBPA }^{\mathrm{d}} \\
\left(\mathrm{Cm}^{2} / 100 \mathrm{~g}\right. \\
)\end{array}$ \\
\hline ISAF & $\mathrm{N} 220$ & 21 & 121 & 116 & 111 & 114 \\
\hline $\begin{array}{c}\text { HAF } \\
\text {-LS }\end{array}$ & N326 & 27 & 87 & 85 & 84 & 71 \\
\hline FEF & N550 & 56 & 41 & 41 & 43 & 122 \\
\hline GPF & N660 & 67 & 35 & 36 & 35 & 91 \\
\hline $\begin{array}{c}\text { SRF- } \\
\text { HS }\end{array}$ & N774 & 79 & 29 & 29 & 30 & 77 \\
\hline
\end{tabular}

aElectron microscope surface area; ASTM D 3849, Dispersion Procedure D (CAB).

${ }^{\mathrm{b}}$ Nitrogen adsorption; ASTM D 3037.

${ }^{\mathrm{c}}$ Cetyltrimethyl ammonium bromide adsorption ASTM D 3765,

${ }^{d}$ Di(n-dibutyl) phthalate ASTM D 2414-90

hours before vulcanization. The vulcanization process was performed according to ASTM: D2084-07 at $153 \pm 2{ }^{\circ} \mathrm{C}$ under a pressure of $4 \mathrm{MPa}$ for 30 minutes. To insure reproducibility, the samples were conditioned at $27^{\circ} \mathrm{C}$ for 30 days [13].

\section{TECHNIQUES OF CHARACTERIZATION}

\section{Mechanical Measurements}

The mechanical test samples were strips of $4 \mathrm{~cm}$ working length and of $16 \mathrm{~mm}^{2}$ initial cross-sectional areas. The strips were cut in the milling direction. The stress-strain measurements were conducted according to ASTM D412-06a (2013) using a homemade tensile testing machine. The sample was attached to two clamps from both sides and the weight was increased by a gear-motor and detected by a digital balance and elongation was recorded instantaneously from a point then the data was calculated from the following relation

$$
\varepsilon(\%)=\frac{\Delta L}{L_{o}} \times 100 \quad \& \quad \sigma=\frac{m g}{A}
$$

Where $L_{o}(\mathrm{~m})$ and $\Delta L(\mathrm{~m})$ are the initial length of the sample and the elongation respectively; $m(\mathrm{~kg})$ is the applied mass, $g$ $\left(\mathrm{m} / \mathrm{s}^{2}\right)$ is the acceleration due to gravity and $A$ is the crosssectional area in $\mathrm{m}^{2}$.

\section{Physico-chemical Measurements}

Swelling measurements of the vulcanized samples were carried out using toluene as a solvent. Disc-shaped samples of $0.5 \mathrm{~cm}$ diameter and $0.2 \mathrm{~cm}$ thickness were cut from rubber sheets. Each sample is weighed by a sensitive balance of $10^{-4} \mathrm{~g}$ accuracy. The test pieces were immersed in the solvent. The swelling took place in glass bottles, kept at a working temperature of $300 \mathrm{~K}$. Every 60 minutes the test piece is removed and dried by a filter paper and weighed. The degree of swelling $Q$ is calculated from the formula

$$
Q=\frac{\left(m-m_{o}\right)}{m_{o}} \times 100 \%
$$

where $m_{o}$ is the initial mass of the rubber sample and $m$ is the mass of swollen rubber sample. After 24 hours; immersion time, the test piece attained the equilibrium swelling [14,15].

\section{Gas Ion Implantation}

The polymer samples of circular shape with common size $(0.79$ $\mathrm{cm}^{2}$ ) were fixed inside the vacuum ended tube with diameter $21 \mathrm{~mm}$. The full length of the accelerating voltage along the evacuated tube was $57 \mathrm{~cm}$. This tube was evacuated several times after refreshing it with oxygen gas to minimize air contamination.

The ignition of microwave (at frequency $2.45 \mathrm{GHz}$ ) lunched to quartz gas tube to generate oxygen ion plasma at fixed gas rate flow that was kept at constant pressure about 0.5 torr. After these steps the ions driving high voltage was applied between the two accelerating plates through a charging capacitor $\mathrm{C}=0.5$ $\mu \mathrm{F}$ and current control resistance of $6 \mathrm{k} \Omega$ (As shown in Fig. 1).

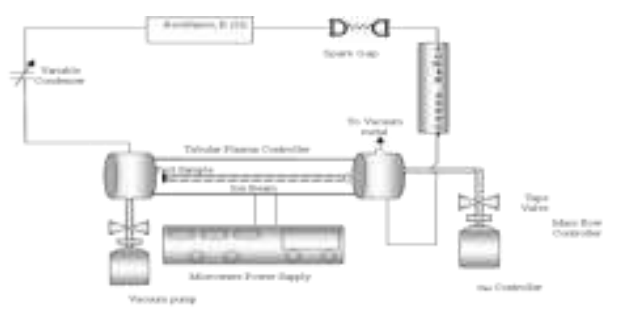

Figure 1 A Schematic Diagram of Tubular Type Plasma Device.

The samples was irradiated with different number of ion shoots with constant accelerating voltage $12 \mathrm{kV}$ between the two copper electrodes of 20 and $10 \mathrm{~mm}$ outer and inner diameter respectively. The influence of oxygen gas irradiation is in the range of $0-3.5 \times 10^{16}$ ions $/ \mathrm{m}^{2}$.

\section{RESULTS AND DISCUSSION}




\section{Mechanical Properties (Effect of Filler Type and Content)}

Different researcher studied stress-strain behavior of the polymer composites with different fillers in the recent era [16]. The nature of deformation of the NBR-carbon rubber composites under an applied load can be understood from the stress-strain curves [17].
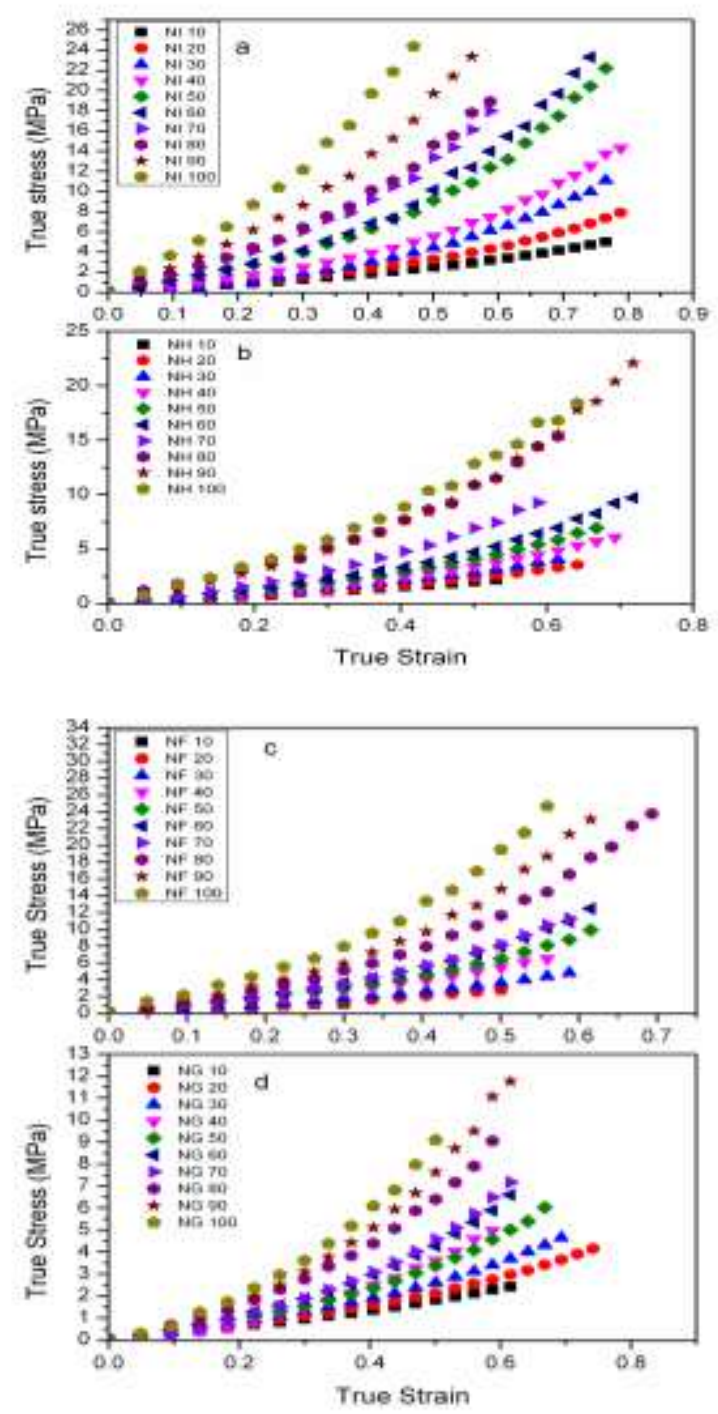

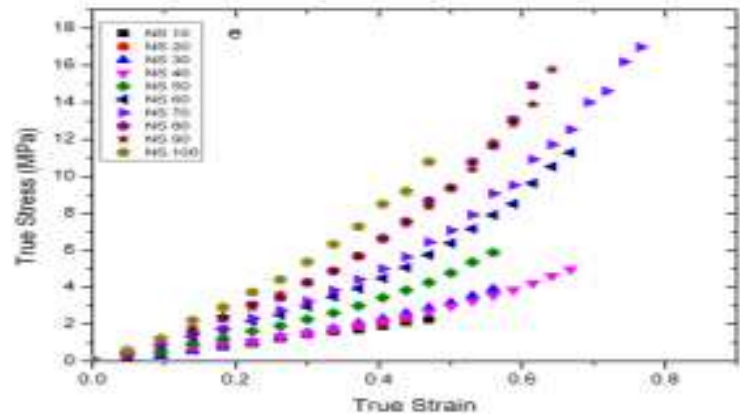

Figure 2. Stress-strain behavior for NBR composites filled with a. ISAF, b. HAF, c. FEF, d. GPF and e. SRF black

The stress-strain behavior of the composites of NBR filled with different concentrations of different carbon black is shown in Fig. (2). These graphs were plotted for composites loaded up to $100 \mathrm{phr}$ of all types of carbon (ISAF, HAF, FEF, GPF and SRF respectively). All filled systems show similar trend as well as high initial moduli. The initial moduli and strength increase with the filler concentration.

\section{Young's Modulus}

Young's Modulus of the composites is the bulk property that attracted more attention in this area of research [16], where it is characterizing the rigidity of the materials, calculated as the slope of the linear part of the stress-strain curve, at low strains (20\%) [17]. As shown in Fig.(3), it is well known that Young's modulus increases for a polymer when we incorporate any reinforcement filler into it. This is reasonable because the ratio of the filler modulus to that of the polymer for all of the various filler-polymer combinations exceeds 30:1 [17].

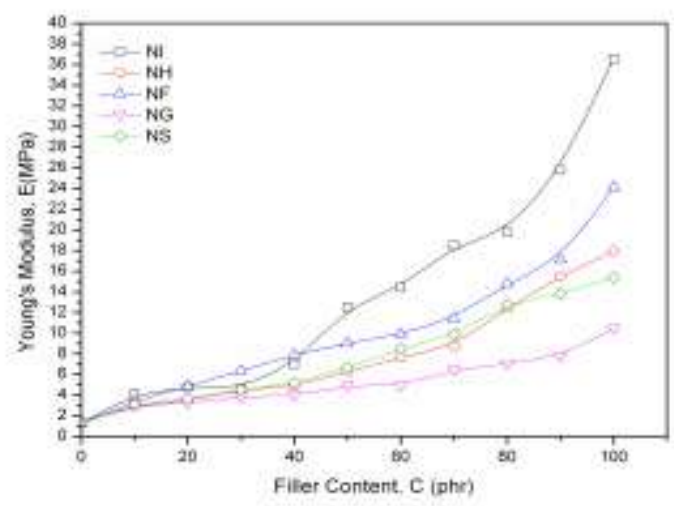

Figure 3. Variation of Young's modulus for NBR composites with carbon black filler type and content 
By increasing the carbon contents for all types the modulus values increased (c.f. Figure 3). The increase in modulus is governed by the fact that the filler gives good reinforcement with the polymer matrix. Also it is attributed to the different parameters of the added filler to the rubber. They include the aspect ratio of the added filler; the orientation of fillers and the nature of filler. In our composites there exists a matrix filler interaction; which enables the Young's modulus increase.

The relative Young's modulus of polymer composite to that of pure NBR matrix $E_{c} / E_{m}$ are plotted in Fig. (4) as a function of both filler type and contents. These plots clearly show that this normalized Young's modulus increases with the filler volume fraction and ISAF filler has the maximum reinforcement with NBR matrix.

However, the curves clearly exhibit the existence of a volume fraction $\phi_{\mathrm{c}}(\approx 30,40,60,70$ and $80 \mathrm{phr}$ for ISAF, HAF, FEF, GPF and SRF respectively), marking the transition between two regions defined by the two different linear dependence on the volume fraction $\phi$. The existence of this concentration was identified with a percolation threshold [17].

In this work, we try to apply Pukanszky et al. $[18,19]$ model to study the behavior of the normalized Young's modulus as a function of both filler type and volume fraction $\phi$.
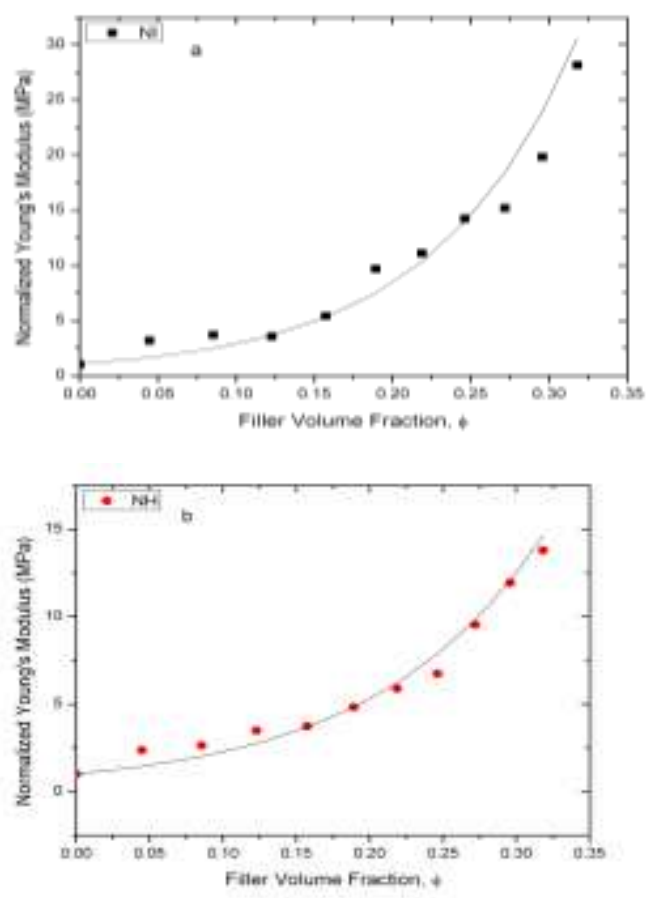
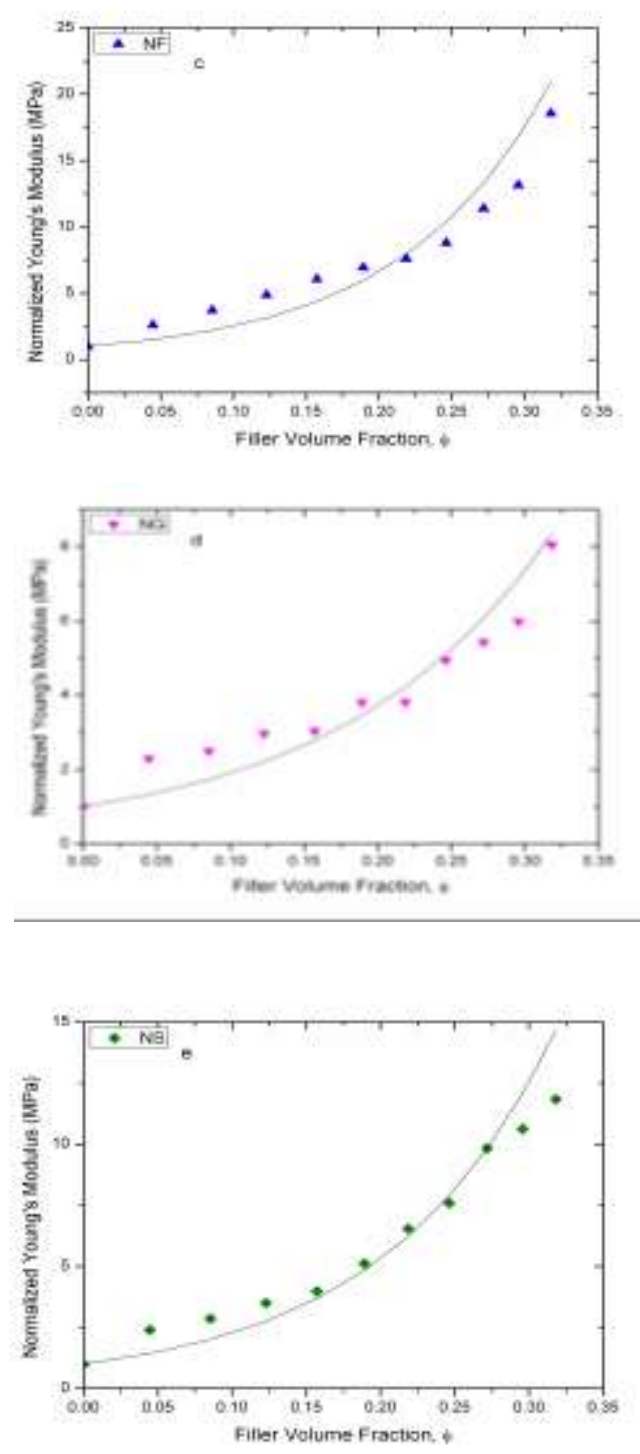

Figure 4. Variation of normalized Young's modulus with filler volume fraction for NBR composites with different carbon black types, points represent experimental values and lines represent Pukanszky et al. model fit.

$$
\frac{E_{c}}{E_{m}}=\frac{1-\phi}{1+2.5 \phi} e^{(B \phi)}
$$

Where the fraction $[(1-\phi) /(1+2.5 \phi)]$ takes into consideration the decrease of the effective load bearing crosssection [20], and the exponential describes all other effects resulting in an increase of the Young's modulus. From the physical point of view, the parameter B is governed by interface and interphase properties. Indeed, as shown by Rong et al.[21] for polypropylene nanocomposites, larger B values correspond 
to higher interfacial adhesion. The following B expression underlines these effects:

$$
B=\left(1+\tau \rho_{f} S_{f}\right) \ln \left(E_{i} / E_{m}\right)
$$

where $\tau$, the thickness of the interphase, is proportional to the interfacial adhesion, defined by the parameter $\zeta_{12}$ with $\tau=\lambda \zeta_{12}$ , where $\lambda$ is a constant. The quantities $\rho_{f}, S_{f}$, and $E_{i}$ represent the density of filler, the specific surface area of the filler and the Young's modulus of the interphase, respectively. Since it is virtually impossible to provide exact values for the absolute thickness $\tau$ and the Young's modulus $E_{i}$ of the interphase, the parameter B was determined from the experimental data using the following expression [17], derived from equation (3):

$$
B=\frac{1}{\phi} \ln \left(\frac{E_{c}}{E_{m}} \frac{1+2.5 \phi}{1-\phi}\right)
$$

Trials to use this model to fit Young's modulus experimental values is illustrated in Fig. (4), one found that this model fits much better the experimental results taking into consideration the different types of carbon filler.

The parameter B is plotted as a function of the volume fraction $\phi$ (for all types of carbon black) for all samples (as shown in Figure (5). All carbon black has the same decreasing trend of the dependence of B on the carbon black concentration.

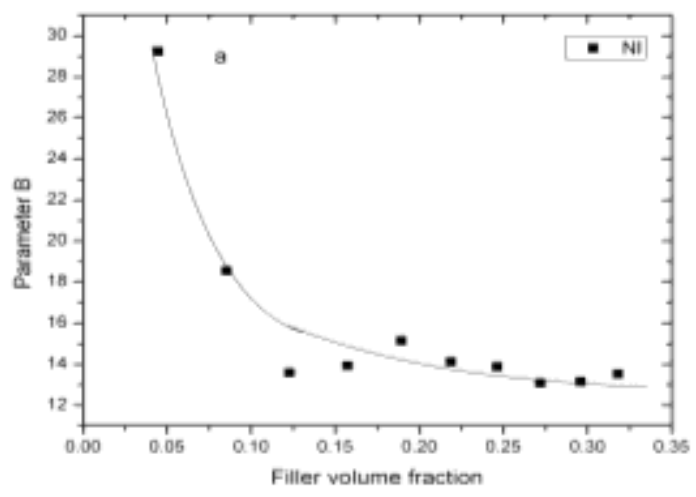

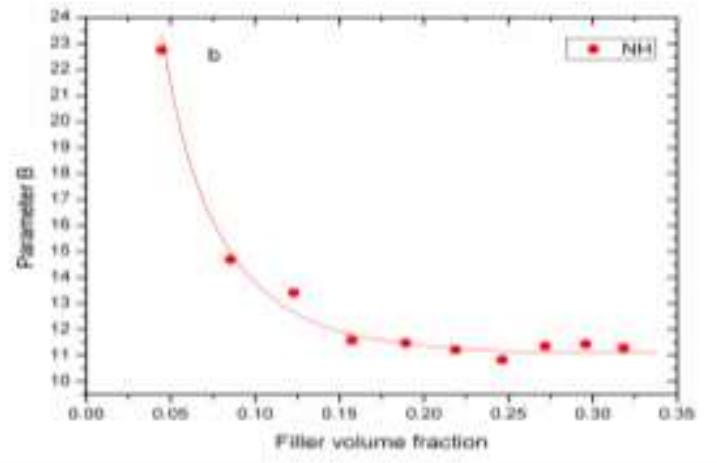
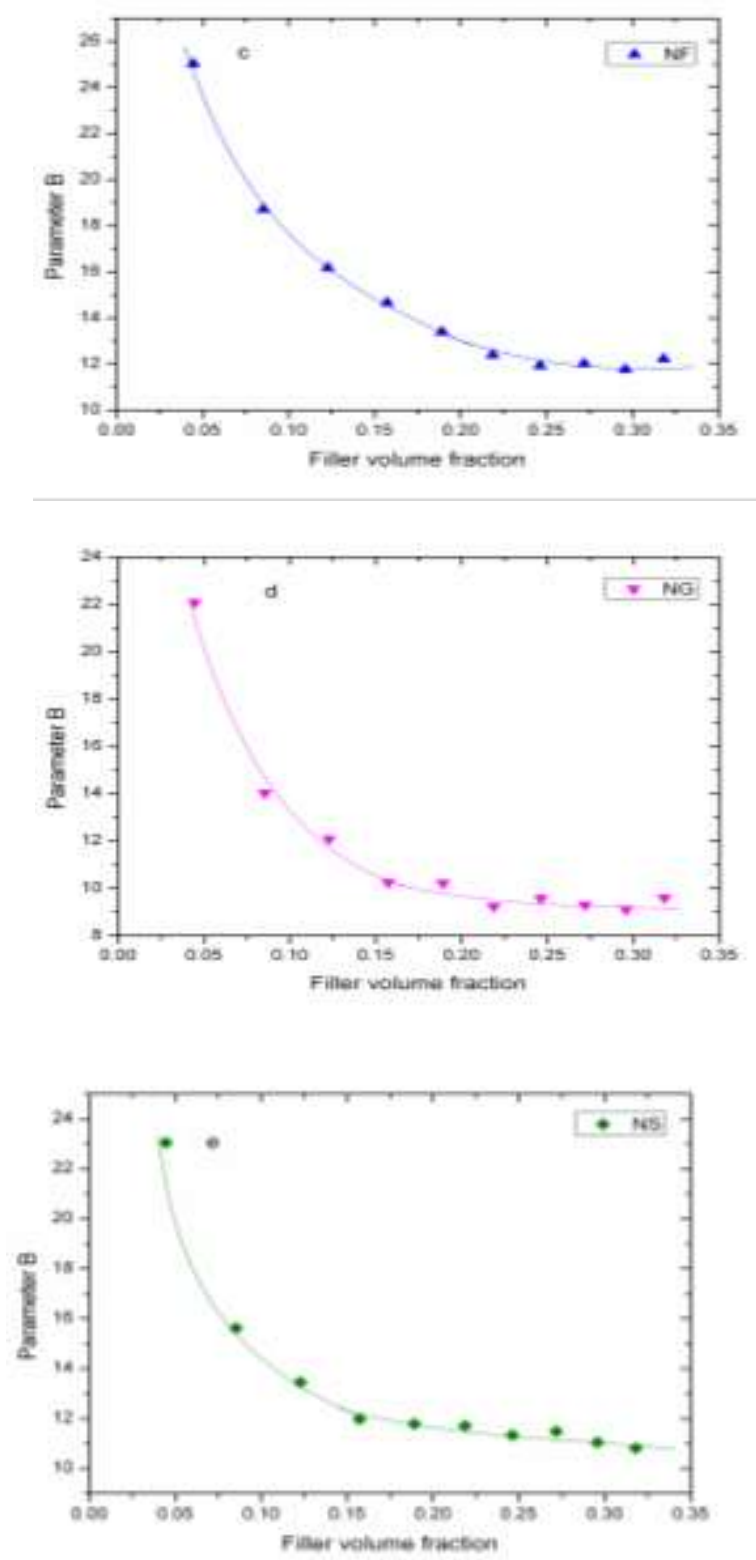

Figure. 5. Variation of parameter $B$ with filler contents of NBR composites loaded with different carbon black types.

Physico-chemical Properties ( Solvent Penetration ) 
Particle size, structure, physical nature, chemical nature, and the porosity are the five most important properties of carbon black, which affect the applications. The smaller the particle sizes the poorer the processibility and the higher the reinforcement. Increase in reinforcement means enhancement of tensile strength, abrasion resistance, and tear resistance.

The chemical nature of the carbon black surface has a direct connection with the properties, which the black confers on rubber. Electrical conductivity and rate of cure thus affected to a considerable degree by the surface chemistry of the carbon black.

Let us now carry out an experiment to study the effect of adding different type of fillers on the penetration rate, $\mathrm{P}$, and diffusion coefficient, $D_{a v}$, of the NBR composites. The diffusion of a liquid in the bulk of the rubber blend depends on the homogeneity of the mix and the way that the filler are aggregated [22]. Hence, the diffusion values are averages over the concentration of liquid and dimensions of the sample.

Diffusion theory in elastomers [23] is based on the assumption that the swelling starts by the sorption of the liquid at the surface of the sample to a certain concentration equal to that attained by the whole sample at equilibrium; then the swelling proceeds by increasing the depth of the swollen layers. The relation between the average diffusion coefficient, $D_{a v}$, and the penetration rate, $P$, is given by $[24,25]$ :

$$
D_{a v}=\frac{\pi P^{2}}{4}
$$

Where $P$ is given by [22]:

$$
P=\frac{1}{2}\left(\frac{M_{t}}{t^{1 / 2}}\right)\left(\frac{d}{M_{e}}\right)
$$

Where, $d$, is the sample thickness, $M_{e}$ and $M_{t}$ are the weight uptake of liquid at equilibrium and after a time, $t$, respectively.

The increase in weight due to swelling (in toluene) for NBR loaded with the percolation concentration of different carbon blacks is plotted against the square root of time, in minutes. The curves are shown in Fig. (6). The effective reinforcement in the rubber matrix is evident from this sorption curves [26]. Vulcanization restricts the long-range movements of the polymer molecules but leaves their local segmental mobility high. Filler reinforcement modifies this condition. The attachment of chains to the surface of the filler has been accomplished through wetting. Carbon blacks can wet polymer segments, because of the increased probability of multiple adsorptions. The highest concentration of bound rubber is in the regions between carbon black particles. This reinforcement restricts the local freedom of movement of macromolecular chains and thereby improves the solvent resistance. Among the different fillers used, NBR loaded with ISAF shows the lowest penetrant interaction. It can be seen that the sorption follows the order: ISAF $30<$ GPF $70<$ FEF $60<$ SRF $80<$ HAF. 40 This trend can be explained on the basis of the difference in filler content, structure, as well as the particle size of fillers reinforced to the matrix. For maximum reinforcement, the filler particles must be of the same size or smaller than the macromolecular chain end-to-end distance [27]. The degree of filler reinforcement increases with decrease in particle size or increase in surface area [28]. Bound rubber increases as the surface area of carbon black increases. The ISAF black possesses the lowest particle size compared to other blacks used and hence executes higher degree of reinforcement. This causes a high resistance to the rubber chain relaxation and thus the free volume within the matrix gets reduced, which subsequently restricts the diffusion of penetrants.

The early linearity of our diffusion curve (see Fig. (6)) may be due to the low equilibrium volume swelling values. The nearly horizontal part of the curve means that, the rubber blend degradation or extraction of its soluble ingredients is extremely small. The slope $\left(\frac{M_{t}}{{ }_{t} / 2}\right)$ of the straight lines at the early part of the curves in Fig. (6), was calculated, and $M_{e}$ was obtained at the equilibrium swelling.

Using equations (6) and (7) the penetration rate, $P$, and the average diffusion coefficient, $D_{a v}$, were calculated for all samples for different fillers (ISAF, HAF, FEF, GPF, and SRF) at percolation concentrations and plotted against the particle size as in Fig. (7) From this figure, it is clear that $P$ and $D$ decrease with decreasing carbon black particle size. This decrease might be the result of the physical crosslinking action induced by carbon black aggregates. These aggregates which exist at different plate lamellae and act as screens reduce the penetration rate of the solvent molecules into the bulk of the rubber mixture [29]. Rubber reinforcement caused by the addition of carbon black restricts the equilibrium swelling. 


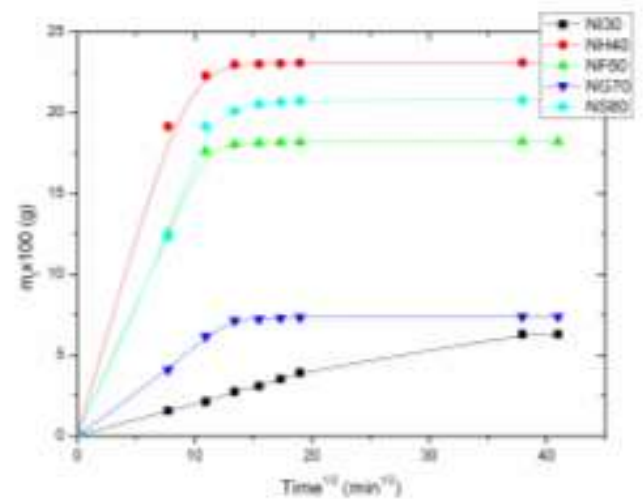

Figure. 6. The increase in weight due to swelling (in toluene) for NBR loaded with the percolation concentration of different carbon blacks (ISAF, HAF, FEF, GPF, and SRF) against the square root of time, in minutes.

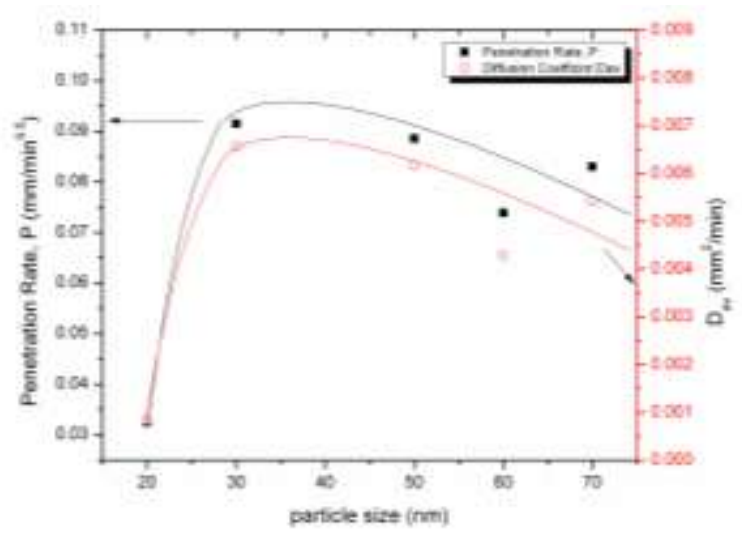

Figure 7. Variation of penetration rate and diffusion coefficient with carbon black particle size.

\section{Swelling Behavior}

The swelling process and its kinetics give an idea about the capacity of cross-linked polymer in different liquids and vapor media [30]. However, the interaction of polymeric materials with solvents is an increasing problem from both the academic and technological points of view [31-34].

The mass and dimension of polymer or rubber systems may be changed due to the penetration of the solvent into swollen specimen. Therefore swelling process may lead to deformation or destruction of the sample microstructure. When a crosslinked polymer is brought into contact with a solvent, the network absorbs a certain amount of liquid which depends strongly on the molecular weight of this liquid and the degree of cross-linked polymer [35, 36]. It was found that the swelling of carbon black filled-rubbers in organic solvents has a large effect on its electrical properties [37].

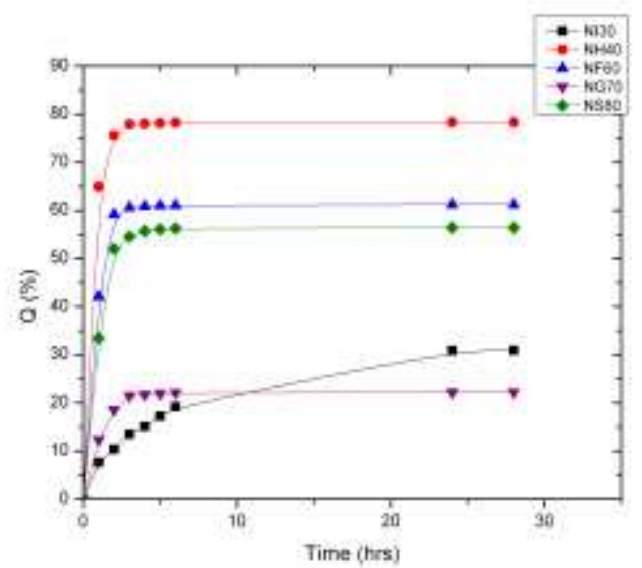

Figure 8. Variation in the degree of swelling Q\%, for NBR loaded with the percolation concentration of different carbon blacks (ISAF, HAF, FEF, GPF, and SRF), with time of swelling, t, in toluene at $303 \mathrm{~K}$

Fig. (8) shows the variation in the degree of swelling $Q \%$ for all rubber vulcanizates, with time of swelling, $t$, in toluene at $303 \mathrm{~K}$. The general behavior may be approximated by an exponential growth function for all samples showing positive swelling mechanism of the form:

Table 3 The fitting parameters $Q_{m}$ and $\tau$ for all rubber vulcanizates.

\begin{tabular}{|c|c|c|c|c|}
\hline Sample & $d(\mathrm{~nm})$ & Area $\left(\mathrm{m}^{2} / \mathrm{g}\right)$ & $Q_{\max }(\%)$ & $\tau(\mathrm{h})$ \\
\hline NI30 & 21 & 121 & 30.91 & 5.5 \\
\hline NH40 & 27 & 87 & 78.37 & 0.79 \\
\hline NF60 & 56 & 41 & 61.22 & 0.85 \\
\hline NG70 & 67 & 35 & 22.19 & 1.09 \\
\hline NS80 & 79 & 29 & 56.42 & 0.96 \\
\hline
\end{tabular}

$$
Q=Q_{m}\{1-\exp (-t / \tau)\}
$$

where, $Q_{m}$ is the degree of maximum swelling and $\tau$ is a characteristic time, which depends on the type of carbon black used, as is clearly observed from Table (3). 
It is noticed that $\tau$ is higher for NBR loaded with $30 \mathrm{phr}$ ISAF and for the rest of samples it increases with increasing of particle size; in other words, the rate of the relative change of swelling, $1 / \tau$, decreases with the increase of the surface area of carbon black.

\section{Ion Beam Irradiation Induced modifications}

Irradiation effects on polymeric material can depend on many factors, such as linear energy transfer (LET), temperature, dose rate, irradiation atmosphere, etc [38].

Most polymeric materials are normally dielectrics and many of them are good insulators. Many methods such as chemical doping [39,40], ion implantation [41,42], laser annealing etc. have been used to alter the polymer properties so that the material becomes conducting. A number of earlier studies [4344] have been established that ion implantation increase the conductivity of the polymer.

The aim of this section is to study the changes in the mechanical properties of the NBR composites loaded with the percolation threshold of the different types of carbon black after implantation with Oxygen ions.

After ion implantations, it was found that the irradiated region becomes dense shiny black. This is ascribed to the beam induced carbonization of the sample. The mechanisms underlying the large improvements for cross-linking in such sensitive mechanical properties as hardness, and the basic parameters to control such changes have not yet been well understood [45].Yet, there is substantial evidence showing that improvements in mechanical properties of polymers induced by ion implantation are largely due to the formation of a threedimensionally connected network formed through crosslinking of polymer chains. Cross-linking produces strong chemically bonded networks, increases rigidity of the backbone structure, provides anchoring points for the chains, and restrains chain movement, thus improving dimensional stability, hardness and elastic modulus, as well as creep resistance [46]. There is also evidence that the linear energy transfer for the ions can be related to changes in hardness. While Pivin stated that the breaking of chains by nuclear collisions has no significant effect on hardening of ion implanted PAN and PIQ [47-48].
Young's modulus for carbon black percolative loading NBR before and after $\mathrm{O}_{2}$ ion beam irradiation is illustrated in Table (4) Comparing the results of Young's modulus obtained before irradiation with those after irradiation, one may notes that it increased by nearly 2-3 times by irradiation and NG70 sample is the most affected sample by irradiation. The modulus of a polymer matrix is proportional to the number of crosslinks formed [49,50]. Since the degree of crosslinking (involving both shorter and longer macromolecular chains) is proportional to the integral radiation dose absorbed by the polymer, an increase in modulus is observed with an increase in radiation dose (as detected by the data of degree of maximum swelling, $Q_{\max }$, in toluene after ion beam irradiation).

Table 4 Values of Young's modulus and degree of maximum swelling for carbon black percolative loading NBR composites before and after $\mathrm{O}_{2}$ ion beam irradiation.

\begin{tabular}{|c|c|c|c|c|c|c|}
\hline & NI30 & NH40 & NF60 & NG70 & NS80 \\
\hline $\begin{array}{c}\text { Young's } \\
\text { modulus } \\
\text { (MPa) }\end{array}$ & Before & 4.63 & 4.86 & 9.89 & 6.43 & 12.78 \\
\cline { 2 - 7 } & After & 9.41 & 9.52 & 13.60 & 17.66 & 20.03 \\
\hline \multirow{2}{*}{$\boldsymbol{Q}_{\boldsymbol{m}} \%$} & Before & 30.91 & 78.37 & 61.06 & 21.52 & 56.45 \\
\cline { 2 - 7 } & After & 19.30 & 54.01 & 42.75 & 13.94 & 35.54 \\
\hline
\end{tabular}

\section{CONCLUSIONS}

From the above results one may summarize:

1. The stress-strain behaviors of the composites show similar trend as well as high initial moduli. The initial moduli and strength increase with the increase in filler concentration.

2. Plots of the relative Young's modulus of polymer composite to that of pure NBR matrix $\mathrm{E}_{\mathrm{c}} / \mathrm{E}_{\mathrm{m}}$ as a function of both filler type and contents show that it increases with the filler volume fraction and ISAF filler has the maximum reinforcement with NBR matrix. 
3. These curves clearly exhibit the existence of a volume fraction $\phi_{\mathrm{c}}(\approx 30,40,60,70$ and $80 \mathrm{phr}$ for ISAF, HAF, FEF, GPF and SRF respectively), marking the transition between two regions defined by the two different linear dependence on $\phi$.

4. Pukanszky et al. model fits well the experimental results of the normalized Young's modulus taking into consideration the different types of carbon filler.

5. Among the different fillers used, NBR loaded with ISAF shows the lowest penetrant interaction; and It can be seen that the sorption follows the order: ISAF $30<$ GPF $70<$ FEF $60<$ SRF $80<$ HAF. 40.

6. The penetration rate, $P$, and the average diffusion coefficient, $D_{a v}$, decrease with decreasing carbon black particle size. This decrease might be the result of the physical crosslinking action induced by carbon black aggregates.

7. the characteristic time of swelling $\tau$ is higher for NBR loaded with $30 \mathrm{phr}$ ISAF and for the rest of samples it increases with increasing of particle size; in other words, the rate of the relative change of swelling, $1 / \tau$, decreases with the increase of the surface area of carbon black.

\section{REFERENCES}

[1] Skelhorn D. Particulate Fillers in Elastomers. In: Rothon RN, editor. Particulate-Filled Polymer Composites. 2nd ed. Shrewsbury, UK: Rapra Tec. Lim.; 2003. p. 324.

[2] McLachlan DS, Chiteme C, Park C, Wise KE, Lowther SE, Lillehei PT, et al. AC and DC percolative conductivity of single wall carbon nanotube polymer composites. Journal of Polymer Science Part B: Polymer Physics. 2005; 43 (22): 3273

[3] DeArmitt C, Rothon R. Fillers and surface treatment. Plastics, Additives and Compounding. 2002; 4 (5):12

[4] Wypych G. Handbook of Fillers. 5th ed. Toronto, Canada: Chem. Tech. Publishing; 2000.

[5] Hohenberger W. In: Zweifel H, editor. Plastics Additives Hanbook. 5th ed. Munich, Germany: Carl Hanser Verlag; 2001. p. 901
[6] Sichel EK, editor. Carbo Black-Polymer Composites: the physics of electrically conducting composites. New York: Marcel Dekker Inc.; 1982.

[7] Chung D. Electromagnetic interference shielding effectiveness of carbon materials. Carbon. 2001; 39 (2): 279

[8] Li JR, Xu JR, Zhang MQ, Rong MZ. Carbon black/polystyrene composites as candidates for gas sensing materials. Carbon. 2003; 41(12): 2353

[9] Avasthi D. Some interesting aspects of swift heavy ions in materials science. CURRENT SCIENCEBANGALORE-. 2000; 78 (11):1297

[10] Mehnert R. Electron beams in research and technology. Nuclear Instruments and Methods in Physics Research Section B: Beam Interactions with Materials and Atoms. 1995; 105 (1): 348

[11] Snell FD, Hilton CL, Ettre LS, editors. Encyclopedia of industrial chemical analysis. New York: Interscience Publisher; 1971.

[12] Corma A, Iborra S, Velty A. Chemical routes for the transformation of biomass into chemicals. Chem Rev. 2007; 107 (6): 2411

[13] Hassan HH, Nasr GM, El-Waily MA. Electrical and mechanical properties of aluminum-loaded NBR composites. Journal of Elastomers and Plastics. 2013; 45 (2): 121

[14] Mahmoud WE. The physical properties of carbon nanoparticles dispersed into NBR/LLDPE nanocomposites for corrosion protection applications. Journal of Applied Polymer Science. 2012; 123 (5): 2667

[15] Tager A. Physical chemistry of polymers. 2nd ed: Mir Publishers Moscow; 1978.

[16] Selvin TP, Kuruvilla J, Sabu T. Mechanical properties of titanium dioxide-filled polystyrene microcomposites. Mater Lett. 2004; 58: 281

[17] Aït Hocine N, Médéric P, Aubry T. Mechanical properties of polyamide-12 layered silicate nanocomposites and their relations with structure. Polymer Testing. 2008; 27 (3): 330

[18] Pukanszky B, VÖRÖS G. Mechanism of interfacial interactions in particulate filled composites. Compos Interfaces. 1993;1 (5): 411

[19] Pukánszky B, Fekete E. Adhesion and Surface Modification. In: Jancar J, Fekete E, Hornsby PR, 
Jancar J, Pukánszky B, Rothon RN, editors. Mineral Fillers in Thermoplastics I: Springer Berlin Heidelberg; 1999. p. 109

[20] Nicolais L, Narkis M. Stress-strain behavior of styrene-acrylonitrile/glass bead composites in the glassy region. Polymer Engineering \& Science. 1971;11(3): 194

[21] Rong MZ, Zhang MQ, Pan SL, Lehmann B, Friedrich K. Analysis of the interfacial interactions in polypropylene/silica nanocomposites. Polymer International. 2004; 53(2):176

[22] Lawandy SN, Wassef MT. Penetration of oils into polychloroprene rubber. Journal of Applied Polymer Science. 1990; 40: 323

[23] Crank J. The mathematics of diffusion: Oxford university press; 1979.

[24] Gwaily SE, Badawy MM, Hassan HH, Madani M. Influence of thermal aging on crosslinking density of boron carbide/natural rubber composites. Polymer Testing. 2003; 22 (1):3

[25] Lawandy SN, Helaly FH. Diffusion of a volatile liquid in polychloroprene rubber. Journal of Applied Polymer Science. 1986; 32(6): 5279

[26] Manoj K, Kumari P, Unnikrishnan G. Cure characteristics, swelling behaviors, and mechanical properties of carbon black filler reinforced EPDM/NBR blend system. Journal of Applied Polymer Science. 2011; 120 (5): 2654

[27] Wang M. Effect of polymer-filler and filler-filler reciprocity to dynamic mechanics performance of filling-vulcanization rubber. Rubber Chem Technol. 1998; 71:520

[28] Blow CM, Hepburn C. Rubber technology and manufacture. 2nd ed. Institution of the Rubber I, editor. London: Butterworth-Heinemann Ltd; 1982.

[29] Amin M, Nasr G, Khairy S, Ateia E. Influence of solvent penetration on the electrical conductance of pre-extended FEF carbon black-loaded rubbers. Journal of Applied Polymer Science. 1989; 37(5):1209

[30] deGennes PG. Sealing Concepts in Polymer Physics. London: Cornell University Press; 1979.

[31] Smith MJ, Peppas NA. Effect of the degree of crosslinking on penetrant transport in polystyrene. Polymer. 1985; 26(4): 569
[32] Ito K. A theoretical approach to the kinetics of polymer degradation in solution. Journal of Polymer Science: Polymer Chemistry Edition. 1978;16 (2): 497

[33] Barton JM. Effect of absorbed water on the thermal relaxation of biaxially stretched crosslinked poly(methyl methacrylate). Polymer. 1979; 20 (8): 1018

[34] Lucht LM, Peppas NA. Macromolecular structure of coals: 2. Molecular weight between crosslinks from pyridine swelling experiments. Fuel. 1987; 66 (6): 803

[35] Cantow HJ, Rschuster RH. Ageing of rubber Polym Bull. 1982; 8: 225.

[36] Gent AN, Liu GL. Diffusion of polymer molecules into polymer networks: Effect of stresses and contraints Journal of Polymer Science, Polymer Physics. 1991; 29: 1313.

[37] Blythe AR, Bloor D. Electrical Properties of Polymers: Cambridge University Press; 2005.

[38] Kudoh H, Celina M, Malone GM, Kaye RJ, Gillen KT, Clough RL. Pulsed e- beam irradiation of polymers-A comparison of dose rate effects and let effects. Radiat Phys Chem. 1996; 48 (5): 555

[39] Bridwell L, editor. Ion Implantation of Polymers for Electrical Conductivity Enhancement. Solid State Phenomena; 1992: Trans Tech Publ.

[40] Mazurek H, Day D, Maby E, Abel J, Senturia S, Dresselhaus M, et al. Electrical properties of ionimplanted poly (p-phenylene sulfide). Journal of Polymer Science: Polymer Physics Edition. 1983; $21(4): 537$

[41] Guenther M, Gerlach G, Suchaneck G, Sahre K, Eichhorn KJ, Wolf B, et al. Ion-beam induced chemical and structural modification in polymers. Surface and Coatings Technology. 2002; 158: 108

[42] Guenther M, Gerlach G, Suchaneck G, Sahre K, Eichhorn KJ, Baturin V, et al. Physical properties and structure of thin ion-beam modified polymer films. Nuclear Instruments and Methods in Physics Research Section B: Beam Interactions with Materials and Atoms. 2004; 216(0):143

[43] Predeep P, Najidha S, Sreeja R, Saxena NS. Surface modification of Natural Rubber by ion implantation: Evidence for implant doping. Nuclear Instruments and Methods in Physics Research Section B: Beam 
International Journal of Science and Engineering Applications

Volume 5 Issue 2, March-April 2016

Interactions with Materials and Atoms. 2005; 240

(4): 850

[44] Najidha S, Predeep P. Electrical and optical properties of nitrile rubber modified by ion implantation. AIP Conference Proceedings. 2014; 1620: 344

[45] Dong H, Bell T. State-of-the-art overview: ion beam surface modification of polymers towards improving tribological properties. Surface and Coatings Technology. 1999; 111(1): 29

[46] Lee E, Rao G, Lewis M, Mansur L. Effects of electronic and recoil processes in polymers during ion implantation. J Mater Res. 1994;9(04):1043

[47] Pivin J. Contribution of ionizations and atomic displacements to the hardening of ion-irradiated polymers. Thin Solid Films. 1995; 263(2):185

[48] Rao G, Lee E, Bhattacharya R, McCormick A. Improved wear properties of high energy ionimplanted polycarbonate. J Mater Res. 1995;10 (01): 190

[49] Banik I, Bhowmick AK. Influence of electron beam irradiation on the mechanical properties and crosslinking of fluorocarbon elastomer. Radiat Phys Chem. 1999; 54 (2):135

[50] Madani M, El-Bayoumi A. Effect of ionizing radiation on physicomechanical properties of surface-treated mica-reinforced high-density polyethylene. Journal of Reinforced Plastics and Composites. 2010; 29 (7):1062 